\title{
Population dynamics of threatened elkhorn coral in the northern Florida Keys, USA
}

\author{
Tali Vardi ${ }^{1, *}$, Dana E. Williams ${ }^{2}$, Stuart A. Sandin ${ }^{1}$ \\ ${ }^{1}$ Scripps Institution of Oceanography, University of California San Diego, La Jolla, California 92037, USA \\ ${ }^{2}$ University of Miami, Miami, Florida 33149, USA
}

\begin{abstract}
Caribbean elkhorn coral Acropora palmata (Lamarck, 1816) was once so widespread and abundant that geologists use its fossils to measure sea levels from the Pleistocene through the Holocene. Now it exists at a small fraction of its former abundance and is listed, along with a congener, as 'threatened' under the US Endangered Species Act. We conducted annual demographic surveys on the northern Florida Keys (USA) population from 2004 to 2010. Percent cover of the benthos, number of colonies, and dominance by large individuals declined throughout the study period. We created population matrix models for each annual interval of the study, which included a severe hurricane year (2005-2006). Hurricane recurrence was simulated stochastically along with multiple outplanting scenarios. Population depletion is predicted given a return time for severe hurricanes of $20 \mathrm{yr}$ or less. Elasticity analysis showed that the largest individuals have the greatest contribution to the rate of change in population size. Active management through outplanting can provide a positive population trajectory over the short term, especially if colonies are reared for several years before transplanting. However, the former abundance of this species suggests that background life history traits, specifically rates of growth versus shrinkage measured herein, are fundamentally different from what they must have been in the past. Ultimately, recovery of this species will depend on enacting local short-term management solutions while improving regional and global environmental conditions.
\end{abstract}

KEY WORDS: Acropora palmata - Caribbean - Demography - Disturbance - Recruitment · Stochastic $\cdot$ Matrix model

Resale or republication not permitted without written consent of the publisher

\section{INTRODUCTION}

Corals are a recent addition to endangered species lists. In 2006, the Atlantic elkhorn coral Acropora palmata was classified as 'threatened' on the US Endangered Species List ${ }^{1}$ along with its congener $A$. cervicornis. Currently, 82 additional corals are considered candidate species (NMFS 2010). In 2008, corals were included on the International Union for Conservation of Nature (IUCN) Red List for the first time. Of all reef-building corals, $33 \%$ with sufficient

\footnotetext{
1On 30 November 2012 NOAA proposed elevating this status to 'endangered' and proposed listing an additional 66 species of coral
}

data were listed as threatened (Vulnerable, Endangered, and Critically Endangered), a percentage rivaled only by amphibians in the animal kingdom (Carpenter et al. 2008, IUCN 2011).

Like many depleted corals, Acropora palmata was neither historically rare nor tightly restricted in its geographic range. Although there are unexplained gaps in the fossil record (Hubbard et al. 2008), the persistence, dominance, and sheer abundance of $A$. palmata throughout time and space qualified it as the dominant shallow-water reef builder in the Caribbean from the late Pleistocene through at least the early Holocene (Adey et al. 1977, Jackson 1992, Hubbard et al. 2005, 2008). During this time, A. palmata was dominant on $80 \%$ of shallow reefs surveyed 
throughout the Caribbean, often forming a monoculture along reef crests and upper reef slopes (Jackson 1992). This percentage dropped to $40 \%$ by 1983 , and to less than $20 \%$ by 1990 (Jackson et al. 2001). Although $A$. palmata is still present throughout its range (Lang 2003), ecological data reveal a continuing decline in abundance. As of 2005, most populations were at 2 to $20 \%$ of the 1970 s baselines (Bruckner \& Hourigan 2000, Carpenter et al. 2008).

The Atlantic Acropora Status Review lists the following stressors to A. palmata: disease, temperature anomalies and bleaching, natural and anthropogenic branch breakage, competition, predation, excessive sedimentation and nutrification, boring sponges, toxic compounds in the water column, loss of genetic diversity, and others (Acropora Biological Review Team 2005). Lists, however, are a deceptively simple presentation of environmental stressors, feedback loops and synergies lurk between the commas (Kline et al. 2006). Further, lists present a snapshot of a dynamic system in which threats can intensify as population abundance declines. For example, coral bleaching episodes are frequently followed by disease outbreaks (Harvell et al. 1999, 2007, Jones et al. 2004). Storms can cause direct physical damage and inflict longer-term damage by fragmenting large colonies into smaller colonies that have higher rates of mortality (Lirman 2003, Williams et al. 2006). Multiple storms can result in the decrease of asexual recruitment via fragmentation (Williams et al. 2008). Also, density of corallivorous snails, particularly Coralliophila abbreviata, on Atlantic acroporids can increase dramatically after hurricanes, impeding or preventing population recovery (Knowlton et al. 1990, Baums et al. 2003, del Mónaco et al. 2011).

Matrix population modeling can offer a glimpse of the immediate future of a population of Acropora palmata colonies. Matrix models are constructed with annual demographic data collected over a time frame appropriate to the life history of an organism. Data are converted into a matrix of transition probabilities, delineating the likelihood of changing from one life stage or size class to another. Each year the number of individuals in each size class is multiplied by the transition matrix, resulting in a projection of the population size structure for the following year. Hughes (1984) developed a size-based matrix model (an adaptation of the classic age-based matrix model) for organisms with a clonal life history, in which individuals can not only grow and die, but also shrink and fragment. For stony corals, shrinking is defined as a reduction in the extent of the skeleton or a reduction in the extent of live tissue covering the skeleton. Fragmentation is a form of asexual reproduction wherein a portion of live coral (skeleton and tissue) breaks off a colony, lands on the substrate, attaches, and forms a new colony (Fig. 1).

\section{a Grow}

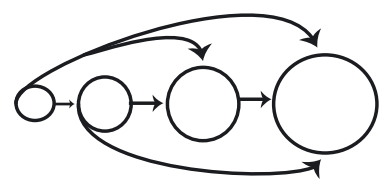

b Loop

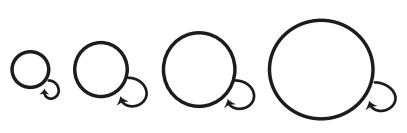

C Shrink

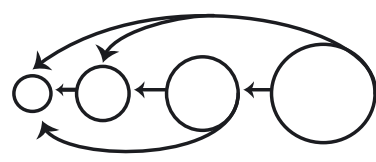

$$
\mathbf{S}=\left[\begin{array}{llll}
0 & s & s & s \\
0 & 0 & s & s \\
0 & 0 & 0 & s \\
0 & 0 & 0 & 0
\end{array}\right]
$$

\section{d New Fragment}

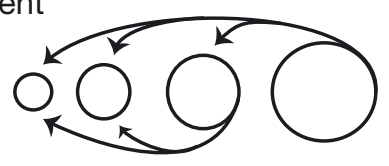

$$
\mathbf{G}=\left[\begin{array}{llll}
0 & 0 & 0 & 0 \\
g & 0 & 0 & 0 \\
g & g & 0 & 0 \\
g & g & g & 0
\end{array}\right]
$$

$$
\mathbf{L}=\left[\begin{array}{llll}
\ell & 0 & 0 & 0 \\
0 & \ell & 0 & 0 \\
0 & 0 & \ell & 0 \\
0 & 0 & 0 & \ell
\end{array}\right]
$$$$
\left[\begin{array}{llll}
0 & 0 & 0 & \ell
\end{array}\right]
$$

$\mathbf{T}=\mathbf{G}+\mathbf{L}+\mathbf{S}$

Fig. 1. Acropora palmata. Life cycle diagram and corresponding matrices. Size classes 1 to 4 are represented by increasing circle sizes. (a-c) Individuals can transition from one size class to any other; they can grow, $g_{i}$ loop (stay in the same size class), $l_{i}$ or shrink, $s$, comprising the transition matrix, T. Although growing more than 1 size class during a transition is mathematically possible, in the model presented here it is biologically possible only through fusion of clonal fragments. (d) Arrival of new fragments, represented by the fragmentation matrix, $\mathbf{F}$, is defined to include new asexually or sexually derived colonies in any of the 3 smallest size classes. (e) General form of the matrix model, A. Subscripts are left off for clarity. Figure modified with permission from Hughes (1984) 
Disturbance is a governing force in coral population structure, and during these events, transition probabilities are characteristically different from those during background conditions (Hughes 1984, Fong \& Glynn 1998, Edmunds 2010). In the Caribbean, storms and hurricanes are the major disturbance events on coral reefs (Gardner et al. 2005) and are thus a critical component for any coral population model. Although Acropora palmata is dependent on a moderate level of wave action for asexual reproduction (Highsmith et al. 1980) and sloughing off sediment (Rogers 1983, Acevedo et al. 1989), severe storms can cause high rates of fragmentation (Lirman 2003) and extreme damage (Woodley 1981, Lirman \& Fong 1997).

We created a size-based matrix model with disturbance for the Acropora palmata population of the northern Florida Keys, USA. We collected demographic data for 7 consecutive years, from 2004 to 2010, from which we estimated annual transition rates for 6 annual intervals (2004-2005, 2005-2006, 2006-2007, 2007-2008, 2008-2009, 2009-2010). With this rich data set, we simulated a stochastic environment by multiplying the population size structure each year by a random draw from the 6 matrices. During our study, the population experienced severe hurricane conditions in 2005; thus 1 snapshot of these disturbance dynamics was captured. Mild storms occurred in the winter of 2004 and summer of 2008, and were considered background conditions along with 2006, 2007, and 2009. We used our population model to determine critical life history stages, predict future population abundance, explore management actions, and provide a realistic time frame for recovery planning for this population.

\section{MATERIALS AND METHODS}

\section{Study site and sampling methodology}

A rapid survey conducted throughout the Florida Keys from 1999 to 2001 found Acropora palmata primarily in high-relief spur and groove reefs and concentrated in the northern Keys (off Key Largo; Acropora Biological Review Team 2005). In this area, 5 of 7 reefs were randomly selected for study. Fifteen non-overlapping, $150 \mathrm{~m}^{2}$ permanent plots distributed among Molasses, French, Elbow, Key Largo Dry Rocks, and Carysfort Reefs were established in 2004 (see Table S1 in the supplement at www.int-res.com/ articles/suppl/n019p157_supp.pdf). Each plot was circular with a radius of $7 \mathrm{~m}$. At the outset of the study, all plots had a minimum of $12 \mathrm{~A}$. palmata colonies. Areas of high A. palmata density (thickets) are no longer typical in this area, and were purposefully excluded so as to manageably track individuals as defined above. Results are thus applicable only to A. palmata stands exhibiting moderate density. For a more detailed description of plot selection, see Williams et al. (2008).

Individuals in this study were defined as neither genets nor ramets, as a distinction between the 2 cannot be made in the field (Miller et al. 2007). Rather, an individual was defined as any continuous live tissue or patches of tissue on the same underlying skeleton (for a complete definition see Williams et al. 2006). Fragments, though clones, were considered reproductive output congruent with the definitions presented by Carpenter et al. (2008) and Highsmith (1982) for all corals. Only ramets attached to the substrate, as opposed to loose fragments, were counted as individuals.

Measuring the size of an Acropora palmata colony is not straightforward. Unlike a boulder coral, it does not have a consistent shape, and unlike a tree, which bears a morphological likeness to the prototypical $A$. palmata colony, there is no standard measurement such as diameter at breast height (Fig. 2). Because corals experience partial mortality, an estimate of the percentage of live tissue is incorporated into our metric. We multiplied the longest axis of the colony (length) and longest perpendicular axis (width) as viewed from above, by a visual estimate of the percentage of live tissue, to estimate 2 -dimensional projected live surface area, or colony size.

Each year, every colony, including any newly attached individual, was identified and measured (as described in detail by Williams et al. 2006). Surveys were conducted in fall 2004, and each spring from 2005 to 2010. The fall survey was between 19 September and 22 October, spring surveys were conducted between 1 May and 1 July, and all surveys were completed within an average of 4 consecutive weeks. In Spring 2005, only 6 of the 15 plots were surveyed, and the remainder were surveyed in the summer. Data from plots surveyed in the spring were used for modeling, but both spring and summer data were used for density estimates (see Table S1 for these abundance data).

\section{Designation of size classes}

We used size, rather than age or stage, to classify individuals, because size classifications lend themselves more easily to estimates of percent benthic 
cover of Acropora palmata on the reef, which is ultimately our topic of interest. Further, Hughes \& Connell (1987) showed that size has a stronger influence than age on coral population dynamics, and Lirman (2000) demonstrated this for A. palmata specifically. Size is also correlated with asexual recruitment in $A$. palmata, because larger colonies have more branches, and branches fragment to produce asexual recruits. Further, living surface area is positively correlated with the amount of gametes a colony produces (Soong \& Lang 1992). We used 2-dimensional projected surface area, which is directly proportional with 3-dimensional surface area, as our size metric (Holmes \& Johnstone 2010, T. Vardi unpubl. data).

Four size classes were defined based on details of the biology and life history of Acropora palmata. Size class 1 (SC1) was defined to include all individuals smaller than $100 \mathrm{~cm}^{2}$, and included both young-ofyear sexual recruits and colonies that may have grown or shrunk into that size range. Given that the highest linear extension rate measured in the Florida
Keys is $10 \mathrm{~cm} \mathrm{yr}^{-1}$ (Acropora Biological Review Team 2005), a new sexual recruit could grow rapidly for a year, and still be a member of the smallest size class. We chose an upper limit of $900 \mathrm{~cm}^{2}$ for SC2 because colonies up to this size typically have a low clonal fecundity due to a lack of long branches. SC3 individuals were defined with an upper limit of $4000 \mathrm{~cm}^{2}$ and as such are more likely than SC2 colonies to have long branches, leading to a higher probability of asexual reproduction. SC4 individuals are defined as those exceeding $4000 \mathrm{~cm}^{2}$, a size at which approximately $90 \%$ of colonies produce gametes (Soong \& Lang 1992); SC4 colonies are thus the most likely to reproduce by both sexual and asexual means.

\section{Model development}

Matrix population modeling (Hughes 1984, Caswell 2001) was used to explore Acropora palmata demography, using the equation
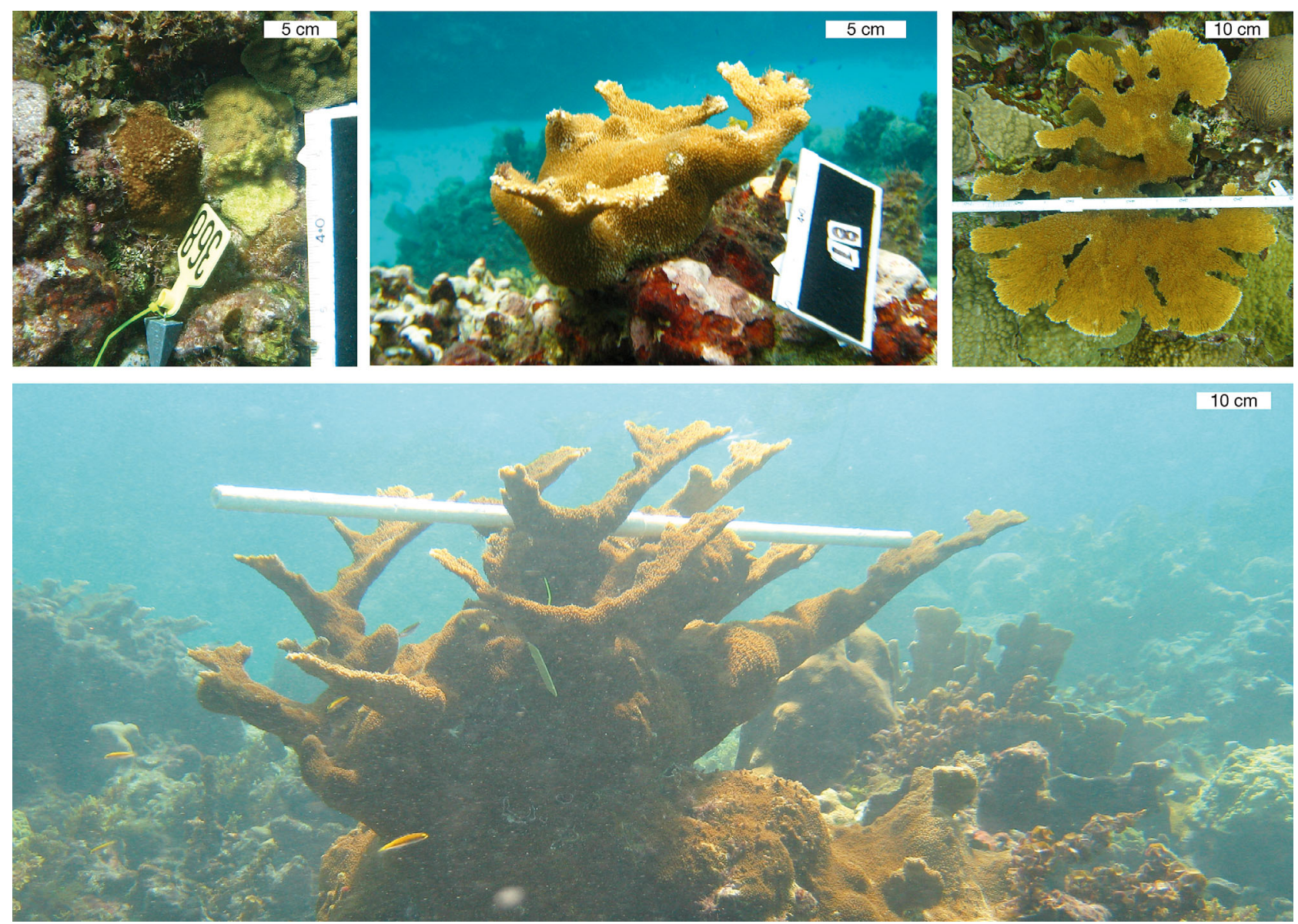

Fig. 2. Acropora palmata. Examples of colonies in size classes 1 to 4, clockwise from top left. Size classes are defined as 0-100, 100-900, 900-4000, and $>4000 \mathrm{~cm}^{2}$, and mean diameters observed were 6.5, 19, 46, and $106 \mathrm{~cm}$ for size classes 1 to 4 , respectively 


$$
\mathbf{n}_{t+1}=\mathbf{A} \mathbf{n}_{t+1}
$$

in which $\mathbf{n}_{t}$ is a vector of the number of individuals in each size class at time $t$. A square matrix with dimensions equal to the number of size classes, $\mathbf{A}$, is the sum of a transition matrix, $\mathbf{T}$, and a fragmentation matrix, F (Fig. 1).

Each value in $\mathbf{T}, t_{i j,}$, represents a probability of transitioning from size class $j$ to $i$ in consecutive time points. Transition probabilities are estimated by summing the number of times a particular transition occurs over a sampling duration and dividing by the number of individuals in $j$. Because the abundance per size class changes each year, each transition is based on a different sample size (see Abundance in Table 1). Corals can grow $(g)$, shrink (s), or stay the same size (l); thus all positions in $\mathbf{T}$ can be $>0$ (Fig. $1 \mathrm{a}-\mathrm{c}$ ). Entries in the fragmentation matrix, $f_{i j,}$ are based on the number of new individuals that arrive in the study area during the same time interval (Fig. 1d). Since sexual and asexual recruits cannot be distinguished in the field (Miller et al. 2007), we combined these 2 categories.

The $\mathbf{F}$ matrix is traditionally known as the fertility matrix. In corals, a measure of fertility would comprise the probability of per-colony gamete release, multiplied by gamete survival. Recruitment would comprise those 2 probabilities multiplied by the probability of larval survivorship in the water column and settlement survivorship. Here we redefine the fertility matrix as the fragmentation matrix, F, since asexual reproduction dominates in Acropora palmata. Though critical for long-term persistence, sexual recruitment events are extremely rare (Bak \& Engel 1979, Edmunds \& Carpenter 2001), and thus can be ignored for shortterm projections of this highly clonal species, as including a sexual recruitment term does not affect the results qualitatively. Therefore, the first row of the fragmentation matrix, $\mathbf{F}_{\mathbf{1 j}}$, incorporates several separate biological processes and their associated probabilities, i.e. the sum of all probabilities of sexual recruitment listed above (since any new colony may have been derived sexually) plus the probability of existing colonies fragmenting multiplied by the survivorship of those fragments until the time of observation, and combines them.

For the $\mathbf{F}$ matrix, we assumed a closed population, where new fragments arise from the existing stand of large (SC3 and SC4) colonies and can be of any size class (although new SC4 fragments were not observed during this study). New SC3 fragments counted in a given year were assumed to derive solely from preexisting SC4 colonies (see Fig. 1d). New fragments of SC1 and SC2 were assumed to derive from existing SC3 and SC4 colonies proportionally, based on the ratio of mean size of $\mathrm{SC} 4$ colonies to that of $\mathrm{SC} 3$, at the beginning of the time step. For $i=1$ or 2 , each year

$$
r_{i}=\left(f_{i 3} \times n_{3}\right)+\left(f_{i 4} \times n_{4}\right)
$$

where $r_{i}$ is the number of new $i$-class fragments at the end of the time step, $f_{i 3}$ and $f_{i 4}$ are the probabilities that an $i$-class fragment is produced by an $\mathrm{SC} 3$ or SC4 colony, and $n_{3}$ and $n_{4}$ are the number of SC3 and SC4 individuals at the beginning of the time step. Given that $q$ is the ratio of mean size of $\mathrm{SC} 4$ to that of $\mathrm{SC} 3$ in a given year, we define:

$$
f_{i 4}=q \times f_{i 3}
$$

Finally, combining Eqs. (2) and (3), we calculate the fragmentation rate of $\mathrm{SC} 3$ as:

$$
f_{i 3}=r_{i} /\left[n_{3}+\left(q \times n_{4}\right)\right]
$$

From the 7 surveys, 6 size-structured matrices were developed, 1 for each time period: 2004-2005,

Table 1. Acropora palmata. Summary of northern Florida Keys coral size range, mean size, and abundance of individuals per size class, as well as stable size distributions and population growth rate $(\lambda)$ based on the respective population matrices in Table 2 . In 2005 , only 6 of the 15 plots were surveyed in the spring; therefore, transition and recruitment rates for 2004-05 and 2005-06 were calculated from colonies in those 6 plots only. The 2 columns for 2006 show abundance in 6 plots and 15 plots, respectively. Abundances from all plots in 2004,2005 , and 2006 are presented in Fig. 3b

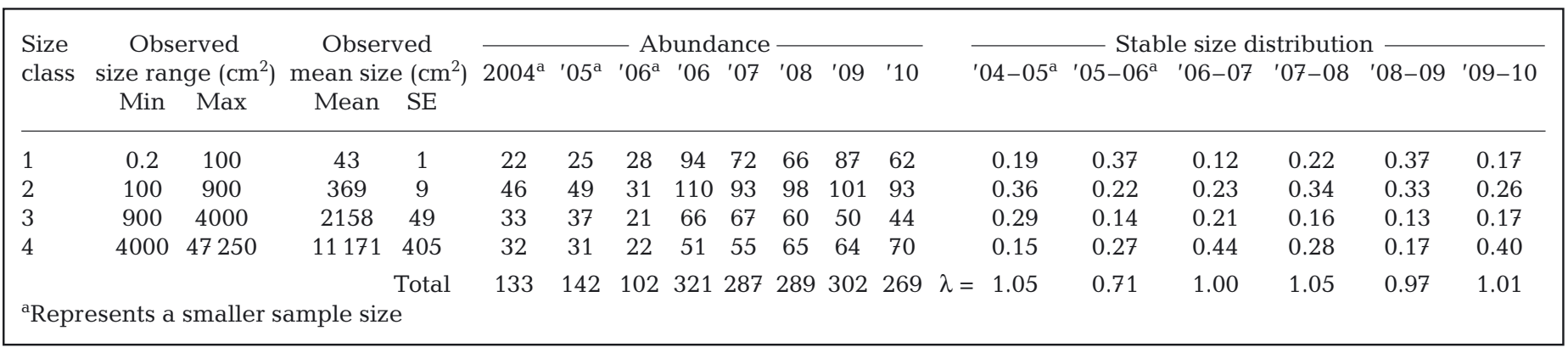


Table 2. Acropora palmata. Annual transition (T), fragmentation (F), and matrix population models (A). Each matrix comprises transition and fragmentation probabilities, or rates, from one size class (SC; column) to another (row). Size-specific mortality (Mort), calculated as 1 - (sum of transition probabilities), is presented underneath each T matrix. $\lambda_{\mathbf{A}}$ : annual rate of change in population size; size classes as in Fig. 2

\begin{tabular}{|c|c|c|c|c|c|c|c|c|c|c|c|c|c|c|c|c|}
\hline \multirow{2}{*}{ Years } & \multirow{2}{*}{$\mathrm{SC}$} & \multicolumn{4}{|c|}{$-\mathbf{T}-$} & \multicolumn{5}{|c|}{$-\mathbf{F}$} & & \multicolumn{4}{|c|}{$\mathbf{A}$} & \multirow{2}{*}{$\lambda_{\mathrm{A}}$} \\
\hline & & 1 & 2 & 3 & 4 & & 1 & 2 & 3 & 4 & & 1 & 2 & 3 & 4 & \\
\hline \multirow[t]{5}{*}{$2004-05^{\mathrm{a}, \mathrm{b}}$} & 1 & 0.60 & 0.07 & 0.00 & 0.00 & + & & & 0.06 & 0.28 & $=$ & 0.60 & 0.07 & 0.06 & 0.28 & 1.05 \\
\hline & 2 & 0.15 & 0.69 & 0.10 & 0.06 & & & & 0.06 & 0.30 & & 0.15 & 0.69 & 0.16 & 0.36 & \\
\hline & 3 & 0.01 & 0.11 & 0.74 & 0.11 & & & & & 0.23 & & 0.01 & 0.11 & 0.74 & 0.34 & \\
\hline & 4 & 0.00 & 0.00 & 0.11 & 0.83 & & & & & 0.00 & & 0.00 & 0.00 & 0.11 & 0.83 & \\
\hline & Mort & 0.24 & 0.13 & 0.05 & 0.00 & & & & & & & & & & & \\
\hline \multirow[t]{5}{*}{$2005-06$} & 1 & 0.44 & 0.14 & 0.08 & 0.00 & + & & & 0.03 & 0.19 & $=$ & 0.44 & 0.14 & 0.11 & 0.19 & 0.71 \\
\hline & 2 & 0.00 & 0.37 & 0.19 & 0.00 & & & & 0.03 & 0.16 & & 0.00 & 0.37 & 0.22 & 0.16 & \\
\hline & 3 & 0.00 & 0.02 & 0.43 & 0.13 & & & & & 0.00 & & 0.00 & 0.02 & 0.43 & 0.13 & \\
\hline & 4 & 0.00 & 0.00 & 0.00 & 0.71 & & & & & 0.00 & & 0.00 & 0.00 & 0.00 & 0.71 & \\
\hline & Mort & 0.56 & 0.47 & 0.30 & 0.16 & & & & & & & & & & & \\
\hline \multirow[t]{5}{*}{$2006-07^{b}$} & 1 & 0.60 & 0.12 & 0.00 & 0.00 & + & & & 0.01 & 0.05 & $=$ & 0.60 & 0.12 & 0.01 & 0.05 & 1.00 \\
\hline & 2 & 0.13 & 0.61 & 0.11 & 0.00 & & & & 0.02 & 0.11 & & 0.13 & 0.61 & 0.13 & 0.11 & \\
\hline & 3 & 0.00 & 0.12 & 0.79 & 0.04 & & & & & 0.00 & & 0.00 & 0.12 & 0.79 & 0.04 & \\
\hline & 4 & 0.00 & 0.00 & 0.09 & 0.96 & & & & & 0.00 & & 0.00 & 0.00 & 0.09 & 0.96 & \\
\hline & Mort & 0.28 & 0.15 & 0.01 & 0.00 & & & & & & & & & & & \\
\hline \multirow[t]{5}{*}{$2007-08$} & 1 & 0.56 & 0.12 & 0.00 & 0.00 & + & & & 0.04 & 0.22 & $=$ & 0.56 & 0.12 & 0.04 & 0.22 & 1.05 \\
\hline & $2^{\mathrm{c}}$ & 0.24 & 0.67 & 0.07 & 0.00 & & & & 0.04 & 0.20 & & 0.24 & 0.67 & 0.11 & 0.20 & \\
\hline & 3 & 0.01 & 0.06 & 0.70 & 0.07 & & & & & 0.04 & & 0.01 & 0.06 & 0.70 & 0.11 & \\
\hline & 4 & 0.00 & 0.00 & 0.21 & 0.93 & & & & & 0.00 & & 0.00 & 0.00 & 0.21 & 0.93 & \\
\hline & Mort & 0.19 & 0.15 & 0.02 & 0.00 & & & & & & & & & & & \\
\hline \multirow[t]{5}{*}{$2008-09$} & 1 & 0.68 & 0.12 & 0.02 & 0.00 & + & & & 0.09 & 0.41 & $=$ & 0.68 & 0.12 & 0.10 & 0.41 & 0.97 \\
\hline & 2 & 0.12 & 0.58 & 0.22 & 0.00 & & & & 0.06 & 0.31 & & 0.12 & 0.58 & 0.28 & 0.31 & \\
\hline & 3 & 0.00 & 0.11 & 0.54 & 0.09 & & & & & 0.03 & & 0.00 & 0.11 & 0.54 & 0.12 & \\
\hline & 4 & 0.00 & 0.00 & 0.07 & 0.91 & & & & & 0.00 & & 0.00 & 0.00 & 0.07 & 0.91 & \\
\hline & Mort & 0.20 & 0.18 & 0.15 & 0.00 & & & & & & & & & & & \\
\hline \multirow[t]{5}{*}{$2000-10$} & 1 & 0.43 & 0.11 & 0.02 & 0.00 & + & & & 0.03 & 0.15 & $=$ & 0.43 & 0.11 & 0.05 & 0.15 & 1.01 \\
\hline & 2 & 0.22 & 0.57 & 0.16 & 0.00 & & & & 0.02 & 0.12 & & 0.22 & 0.57 & 0.18 & 0.12 & \\
\hline & 3 & 0.00 & 0.08 & 0.54 & 0.09 & & & & & 0.05 & & 0.00 & 0.08 & 0.54 & 0.14 & \\
\hline & 4 & 0.00 & 0.00 & 0.24 & 0.91 & & & & & 0.00 & & 0.00 & 0.00 & 0.24 & 0.91 & \\
\hline & Mort & 0.35 & 0.24 & 0.05 & 0.00 & & & & & & & & & & & \\
\hline
\end{tabular}

2005-2006, 2006-2007, 2007-2008, 2008-2009, and 2009-2010 (Table 2). Since the first time period was $6 \mathrm{mo}$, and all others were annual, the first matrix was squared to make it comparable to the remaining matrices (Caswell 2001). Performing this calculation assumes that transition and recruitment from fall to spring are equivalent to those from spring to fall. Projections were run without these data from 2004-2005 and showed the same qualitative output.

\section{Log-linear analyses}

We were interested in determining whether sites differed significantly from one another or were similar. If sites were deemed similar, then they could be combined into a single population of Acropora palmata in the northern Florida Keys. Using the $\mathbf{T}$ matrices from each year, we built 2 log-linear equations based on transition counts (as in Caswell 2001). One equation included the effects of all possible factors (starting size class, ending fate, site, and year of transition) and their interactions. The other excluded site effects. If site effects are significant, then the first, fully parameterized equation will fit the data better than the second under-parameterized equation.

The saturated equation is written in terms of 4 factors: $S$, initial state or size class; $F$, ending fate, including death, growth, or shrinkage to another size class; $X$, site; and $T$, time. The probability that an individual starts at state $i$, location $k$, and time $l$ and ends up with fate $j$ is the product of the probabilities that define those variables. The logarithm of the sum of individuals with particular starting and ending conditions is the sum of the effects of these variables 
(Caswell 2001). This saturated equation can be written as:

$$
\begin{aligned}
F S X T: \log m_{i j k}= & u+u_{S(i)}+u_{F(j)}+u_{X(k)}+u_{T(l)}+ \\
& u_{S F(i j)}+u_{S X(i k)}+u_{S T(i l)}+u_{F X(j k)}+ \\
& u_{F T(j l)}+u_{X T(k l)}+u_{S F X(i j k)}+u_{S F T(i j l)}+ \\
& u_{S X T(i k l)}+u_{F X T(j k l)}+u_{S F X T(i j k l)}
\end{aligned}
$$

The under-saturated equation excluding all $X$ and $F$ interactions is

$$
\begin{aligned}
F S T, S X T: \log m_{i j k}= & u+u_{S(i)}+u_{F(j)}+u_{X(k)}+ \\
& u_{T(l)}+u_{S F(i j)}+u_{S X(i k)}+ \\
& u_{S T(i l)}+u_{F T(j l)}+u_{X T(k l)}+ \\
& u_{S F T(i j l)}+u_{S X T(i k l)}
\end{aligned}
$$

where $m_{i j k l}$ is the number of individuals in state $i$ from location $k$ at time $l$ ending with fate $j, u$ is the log of the total number of observations in each table, $u_{S(i)}$ is the effect of the $i$ th state, and $u_{S F(i j)}$ is the effect of the interaction of the $i$ th state and the $j$ th fate, and so on.

The equations are parameterized using maximum likelihood and compared using a chi-squared distributed goodness-of-fit test where:

$$
G^{2}=2 \times \sum_{\text {cells }} \text { observed } \times \log \left(\frac{\text { observed }}{\text { expected }}\right)
$$

\section{Model analyses}

Long-term rate of change in population abundance, $\lambda$, and stable size distribution were calculated by taking the eigenvalue and right eigenvector of each matrix. In addition, stochastic growth rate, $\lambda_{\mathrm{s}}$ was estimated from the average growth rate over a long (50 000 yr) simulation (Caswell 2001, Stubben \& Milligan 2007). Since each matrix captures annual variation in population dynamics (i.e. a stochastic environment), $\lambda_{\mathrm{s}}$ yields a more robust estimation of the long-term rate of change than any annual matrix or even the mean matrix can provide. In all cases, simulations matched Tuljapurkar's approximation for the same parameter (see Caswell 2001). Several calculations utilize the mean matrix, $\mathbf{A}_{\mathrm{m}}$, which is simply a matrix with dimension equal to that of $\mathbf{A}$, wherein each element $a_{i j}$ is the arithmetic mean of the corresponding $a_{i j}$ from each matrix. Elasticity values

$$
e_{i j}=a_{i j} / \lambda \times \partial \lambda / \partial a_{i j}
$$

were calculated to determine the relative contribution of each matrix element on lambda (Caswell 2001). These calculations utilized the 'popbio' package in R (Stubben \& Milligan 2007).

\section{Population projection and scenarios}

From a management perspective, it is critical to explore population projections among likely environmental scenarios. For Acropora palmata, the most important and variable physical forcings are hurricanes, specifically the frequency (defined as $1 / h$, where $h$ is the return time in years) of major hurricanes affecting a particular population (Gardner et al. 2005). During the 2005-2006 interval, 4 major hurricanes (category 3 or greater) traveled within 200 nautical miles (n miles) of the study area, 3 of which caused significant damage to the existing population. Single storms can produce a net gain in terms of population abundance, via branch breaks. However, consecutive storms can (and did) result in a net loss, when fragments are swept away before reattachment can occur. Since the majority of the damage in 2005 was inflicted by 2 consecutive storms, we calculated the return time of 2 or more major storms occurring within a $200 \mathrm{n}$ mile radius of our study. Based on annual data collected since 1851, this return time, $h$, is $20 \mathrm{yr}$ (NOAA 2011). Thus $h=20$ represents a relatively realistic scenario for a stochastic simulation. To bound these results, we explored 2 alternate return times. As a lower bound, we assumed that our study period was representative, making the implicit assumption that a year as severe as 2005-2006 recurs every 6 yr $(h=6)$. As an upper bound, we assumed a year as destructive as 2005-2006 would never return $(h=\infty)$. We thus simulated a stochastic environment by randomly selecting 1 of the 6 annual matrices, where the probability of selecting the hurricane matrix was $1 / h$ and the probabilities of selecting each of the other 5 matrices were equal to each other and defined as $[1-(1 / h)] / 5$. All hurricane scenarios were run for $20 \mathrm{yr}$ (until 2030) and for $50 \mathrm{yr}$ (until 2060) to contextualize the earlier time frame and to show any potential differences between shorter- and longerterm dynamics.

One of the few Acropora palmata management actions available is outplanting colonies reared in nurseries. We simulated outplanting both SC1 and SC2 colonies at 3 density levels $(1000,2000$, and 3000 outplants over the $2300 \mathrm{~m}^{2}$ study area) that match density levels currently used for Acropora cervicornis (S. Griffin pers. comm.). We did not modify transition rates for outplants, but rather assumed that the same rates of growth, shrinkage, and mortality would apply. Mean rates of mortality measured in our study, 30 and $21 \%$ for SC1 and SC2, respectively, roughly matched that of similarly sized A. cervicornis outplants $(20 \%$; T. Moore pers. comm.). The 20 yr pro- 
jection period comprises $2 \mathrm{yr}$ with no planting, $5 \mathrm{yr}$ with planting, and an additional $13 \mathrm{yr}$ with no planting. Outplanting was incorporated into the model explicitly by adding 1000, 2000, or 3000 individuals to SC1 or SC2, for each time step (year) of the $5 \mathrm{yr}$ planting period. Results are shown after 5 and $20 \mathrm{yr}$ (in the years 2017 and 2030). All outplanting scenarios were projected using the same matrices and Markovian processes as the hurricane scenarios with $h=$ $20 \mathrm{yr}$. We used size-class specific abundances in 2010 to seed all population projections (see Table 1).

Percent cover was calculated by multiplying the number of individuals in each size class in the final year of the projection by the mean size of the corresponding size class (see Table 1), and dividing the sum of those numbers by the total study area $\left(2309 \mathrm{~m}^{2}\right)$. This method assumes that colonies do not overlap, thereby potentially overestimating total percent cover for any projection. All calculations were conducted using R (R Development Core Team 2011). Projected estimates of population size and structure are based on 10000 simulations. All confidence intervals (CI) presented are at the $95 \%$ level.

\section{RESULTS}

\section{Annual surveys}

During the course of our study from 2004 to 2010, Acropora palmata cover decreased $40 \%$, from 6.6 to $3.9 \%$, and abundance decreased $21 \%$, from 340 to 269 individuals (Fig. 3a,b). In addition, mean size within each size class declined by $13,19,1$, and $18 \%$ for SC1 through SC4, respectively. The proportion of individuals classified as reproductively viable (including sexual and asexual reproduction, i.e. SC3 and SC4) declined from 52\% in 2004 to $42 \%$ in 2010 (Fig. 3c).

\section{Log-linear analyses}

We used a goodness-of-fit to test the hypothesis that site (or reef) was an important factor explaining differences in the number of transitions from a particular state to a particular fate through time. The null hypothesis was that the effects of site on fate do not help explain the variability in the data; in other words, that an under-saturated equation (FST, SXT), which excludes all interactions of site on fate, is sufficient to describe observed transitions. There was insufficient support to reject the null hypothesis at the $p=0.05$ level, suggesting that accounting for different sites does not significantly improve the power of explanation. The results from this test (goodness of fit $=241.622, \mathrm{df}=448, \mathrm{p}=1.00$ ) suggest that variation in transition rates among reefs was similar.

\section{Matrices}

Mortality was highest for the smallest size classes and survivability increased with each successive size class (Table 2). Probabilities of shrinkage from one size class to the next were as high as 0.22 , and rates of growth from one size class to the subsequent were as high as 0.24 . Growing 2 size classes in 1 yr was uncommon (occurring twice) in comparison to shrinking more than 1 size class, which happened a total of 8 times. The number of new fragments in a given year ranged between 10 and 58, with smaller recruits consistently outnumbering larger ones.

Most commonly, individuals tended to remain in the same size class from one year to the next (Table 2). Except mortality in SC1 and SC2 in 2005-2006, the probabilities of stasis (the loop probabilities along the main diagonal of the matrix) were larger than any other probability per size class per year, over all years and size classes. SC4 had the highest probability of stasis, experiencing 0 mortality in all years except 2005-2006. In Fig. S1 in the supplement at www.int-res.com/articles/suppl/n019p157_supp.pdf, we show that $e_{44}$, the elasticity of SC4 surviving and not shrinking, was greater than the elasticity of any other matrix element, $e_{i j}$, across all years, meaning that adult survival had the largest contribution to population growth rate, $\lambda$, compared with all other transitions. This was true during background conditions (Fig. S1a,c-f), as well as during severe storm conditions (Fig. S1b). Elasticity analyses performed on the mean matrices of the 3 hurricane scenarios showed similar qualitative results to those emerging from the deterministic 1 yr matrices shown in Fig. S1. Thus, we present only the results from the 1 yr, deterministic matrices in order to show the general pattern of parameter elasticities and the extremes revealed from these data. Importantly, if more precise elasticities for particular stochastic scenarios are required for management or other applications, targeted analytical approaches are available (Tuljapurkar et al. 2003).

The dynamics of Acropora palmata during a severe hurricane year were captured in the 2005-2006 population matrix (Table 2). Survivorship (1 - mortality) during 2005-2006 for all size classes was markedly 
lower than that for all other years $(0.44,0.53,0.70$, 0.84 for -2006 for SC1 to SC4, respectively, versus mean $\pm \mathrm{SE}, 0.76 \pm 0.04,0.84 \pm 0.03,0.95 \pm 0.03,1.00$ \pm 0.00 for the other 5 years). Similarly, the probability of growth for all size classes in 2005-2006 was less than that of background years by 1 order of magnitude (mean $\pm \mathrm{SE}, 0.01 \pm 0.00$ versus $0.10 \pm 0.01$, based on the mean matrix for those years).

Annual population growth rate, $\lambda$, calculated from each matrix ranged from 0.71 to 1.05 (Table 1), and was 0.96 based on the mean matrix. Thus, for every 100 colonies, an average of 4 died each year. Since 2005-2006 was an extreme year, stochastic growth rate, $\lambda_{s}$, depends on the probability of its recurrence, $1 / h$, and was estimated for $h=6$ as $0.956(95 \% \mathrm{CI}=$ 0.955-0.957), for $h=20$ as 0.999 (95\% CI $=0.998-$
1.000), and for $h=\infty$ as 1.019 (95\% CI = 1.018-1.020). Thus, assuming a year like 2005-2006 recurs every $20 \mathrm{yr}$, the population is slowly declining.

\section{Projections}

Without intervention by 2060, and under a modest hurricane recurrence scenario $(h=20)$, projected benthic cover of Acropora palmata (mean $=4.5 \%$, $95 \% \mathrm{CI}=0.9$ to $11.2 \%$ ) is nearly unchanged from that in 2010 (3.9\%; Fig. 3a). Predicted mean abundance in 20 and $50 \mathrm{yr}$ is also nearly equivalent to starting abundance (Fig. 3b). Note that the estimated stochastic growth rate for $h=20$ was estimated as slightly less than 1 (0.999), while short-term projec-
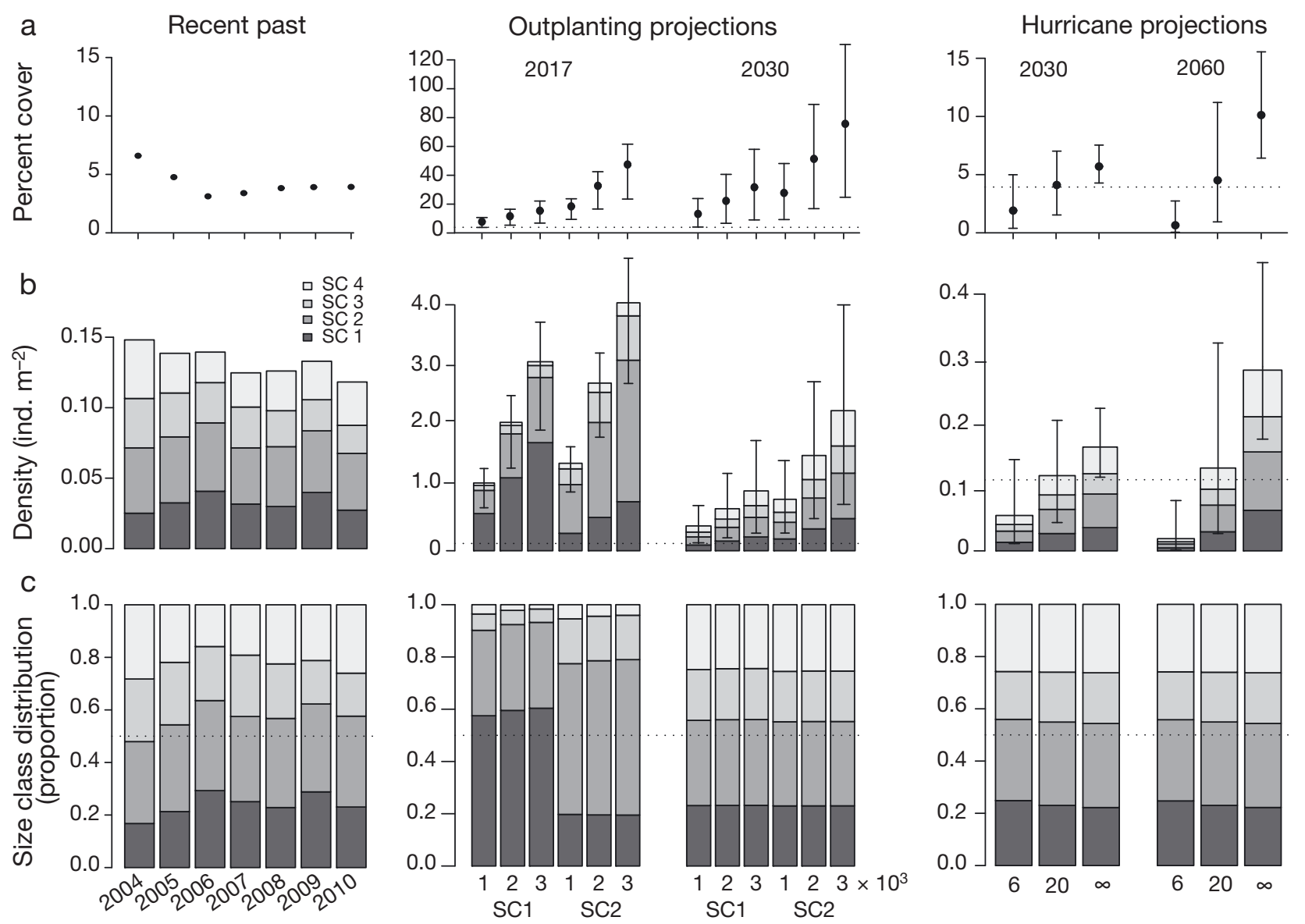

Fig. 3. Acropora palmata. (a) Percent cover, (b) density, and (c) proportional size class distribution, as observed over the course of the study from 2004 to 2010 (2005 spring and summer surveys combined; left panels), as projected after 5 yr of outplanting (center panels), and as projected under different hurricane return times: 6, 20, and an infinite number of years (right panels). The outplanting projections have a 2 yr lag time with no outplanting, followed by 5 yr of outplanting either size class 1 (SC1) or size class 2 (SC2) outplants at 3 densities $\left(1000,2000\right.$, or 3000 outplants over the $2300 \mathrm{~m}^{2}$ study area). Results are shown immediately following $5 \mathrm{yr}$ of outplanting (in the year 2017) and $13 \mathrm{yr}$ after the end of outplanting (2030). The hurricane scenarios are projected for 20 and $50 \mathrm{yr}$, to 2030 and 2060. All results are means based on 10000 simulations. Error bars represent a $95 \%$ confidence interval on percent cover and total abundance. Dotted lines represent (a) percent cover or (b) abundance as measured in 2010, and (c) $50 \%$ 
tions (20 and $50 \mathrm{yr}$ ) suggest slightly positive growth. This distinction is due to the time scales of estimation; $\lambda_{\mathrm{s}}$ is calculated over a $50000 \mathrm{yr}$ simulation, while these projections were on decadal scales.

Abundance and percent cover change predictably with $h$. When $h=6$, mean cover is reduced to less than $2 \%$ by 2030 and less than $1 \%$ by 2060 (Fig. 3a). When $h=\infty$, a modest increase in cover to $5.7 \%(95 \%$ $\mathrm{CI}=4.3$ to $7.5 \%$ ) is projected in $20 \mathrm{yr}$, and a doubling of population abundance is projected for 2060 (Fig. 3b). The proportion of individuals in each size class by the end of any projection of $20 \mathrm{yr}$ or more (including outplanting projections; Fig. 3c) is equivalent to the stable size distribution derived from the mean matrix. The convergence to a stable size distribution could occur as early as $8.6 \mathrm{yr}$, using the approach for estimating time to convergence from Doak \& Morris (1999).

Finally, size of outplants matters. At the most dense outplanting scenario (1.3 outplants $\mathrm{m}^{-2}$ or 3000 outplants over the $2300 \mathrm{~m}^{2}$ study area), cover using SC2 outplants (mean $47 \%, 95 \% \mathrm{CI}=23-61 \%$ ) is significantly higher than that using SC1 outplants (mean $15 \%, 95 \% \mathrm{CI}=7-22 \%$ ) after $5 \mathrm{yr}$ of outplanting (Fig. 3a). Analogous comparisons of the other SC2 outplanting densities, $0.43 \mathrm{~m}^{-2}$ and $0.87 \mathrm{~m}^{-2}$ (1000 and 2000 outplants over $2300 \mathrm{~m}^{2}$ ), revealed a similar pattern resulting in higher percent cover, although the CIs overlapped. Even in the worst-case scenarios (i.e. lower confidence boundaries), 5 yr of SC2 outplantings are predicted to increase percent cover from current conditions, represented by the dotted line in Fig. 3a. This relationship holds at least until 2030. The same is not true for the SC1 outplanting scenarios. Interestingly, although abundance is predicted to decline between 2017 and 2030 for all outplanting scenarios (Fig. 3b), mean percent cover is predicted to increase (Fig. 3a). Comparing the proportional size class distribution in 2017, dominated by SC1 and SC2 individuals, to that in 2030, which has a more even size class distribution (Fig. 3c), we see that the increase in percent cover is due to growth of outplants into bigger size classes over time.

\section{DISCUSSION}

\section{Modeling results}

During the 7 yr of our study, we saw declines in percent cover and mean size of individuals. The demographic rates we measured reveal that while this population of Acropora palmata could persist at or near presently low levels of abundance for the next $50 \mathrm{yr}$, without active management the population will not recover to former levels of abundance.

Although $\lambda$ is the standard currency of population biology, it can be a misleading metric when applied to the life history of clonal sessile organisms if size structure is not considered. Our most realistic assessment of $\lambda$ is just below 1.00 (at $h=20$ ), not a drastic rate of decline in population size for a threatened species. However, we documented a shift in size structure from the inception of the study, wherein larger, reproductive size classes with high survivorship dominated $(52 \%)$, to the end of the study, wherein smaller, prereproductive size classes with lower survivorship dominated (58\%). This trend is confirmed by the stable size distribution of the mean matrix, which provides the best estimate of how the size classes ultimately will be distributed. Here, smaller size classes also dominated (56\%). Similarly, Hughes \& Tanner (2000) saw a shift in dominance from largest to smallest size class in 2 coral species over a 16 yr study period. These patterns are slow to emerge, yet are a critical sign of decline in the overall health of coral populations, as smaller sizes in general have lower survivorship and fecundity (Highsmith 1982).

Note that CIs widen as projection intervals lengthen, a phenomenon common to all stochastic simulations. The wide CIs on abundance and percent cover estimates can be considered either representative of a stochastic environment or an artifact of our model choice. Prior coral simulation models set the return time of a storm deterministically at varying intervals and simulated background conditions in the interim years (e.g. Hughes 1984, Lirman 2003, Edmunds 2010). There is utility in this approach, as it quantifies the resilience of corals to storms. Further, this is the only option unless more than 2 demographic surveys have been conducted. We felt that our time series was sufficiently long to simulate a stochastic environment and assign a probability of hurricane recurrence. This means that some simulations will have more 'bad years' than others, and the resulting response variables thus have a wide CI. Here we present results using a CI of $95 \%$, but from a management perspective, focusing on the lower limit of a narrower CI may be more appropriate.

\section{Management recommendations}

The top 3 stressors to Acropora palmata in the northern Florida Keys (fragmentation, disease, and snail predation) have accounted for $85 \%$ of tissue 
loss since 2004 (Williams \& Miller 2012). Fragmentation, due primarily to storms, cannot be stopped (although rescued fragments can be stabilized), and coral diseases are currently incurable. Snails, however, can easily be removed from colonies. Coralliophila abbreviata is a known threat to already depressed acroporid populations, capable of destroying remnant populations in the months and weeks after a storm (Knowlton et al. 1990, Baums et al. 2003). Indeed, C. abbreviata density (relative to live tissue area) increased 4 -fold over the course of the present study, and accounted for $25 \%$ of lost live tissue, excluding the 2005 storm season (Williams \& Miller 2012). Snail removal has been shown to preserve $75 \%$ more live $A$. palmata tissue compared with controls where snails are left in place (Miller 2001). Importantly, this management action can target SC4 colonies, which have the greatest influence on population increase, as demonstrated by elasticity analyses.

Outplanting is currently the only recovery strategy being actively pursued by managers. Outplanting can provide a short-term boost to currently depressed demographic rates in a small geographic area, while long-term strategies to improve environmental conditions are being pursued. We limited these projections to $20 \mathrm{yr}$, as models predict short-term trajectories best, and the influx of colonies leads to a widening of CIs. Unsurprisingly, after $5 \mathrm{yr}$ of planting, in 2017, abundance is higher and distribution is dominated by the size class that was planted (Fig. 3b). Thirteen years after the cessation of planting, in 2030, the size class distribution stabilizes (Fig. 3c). At this point, mean abundances have decreased relative to the abundance in 2017; however, mean percent cover estimations are greater in 2030 than those projected for 2017.

We found that planting 3000 SC2 colonies (mean diameter $19 \mathrm{~cm}$ ) resulted in significantly higher mean percent cover by 2017 than planting 3000 SC1 colonies (mean diameter $6.5 \mathrm{~cm}$ ) over the study area (1.3 outplants $\mathrm{m}^{-2}$ ). Furthermore, although planting SC1 colonies could increase cover to $60 \%$ by 2030 under the best conditions (upper CI boundary), managers would be wise to focus on the value of the lower CI boundary, which represents unfavorable conditions (Fig. 3a). Here, cover could make a more modest improvement $(9 \%)$ over current conditions $(4 \%)$. In contrast to the SC1 scenario, planting 3000 $\mathrm{SC} 2$ colonies results in a worst-case scenario (lower CI boundary) of $24 \%$ cover. Thus, according to our model, a 5 yr dense SC2 outplanting regime does a fair job of preventing population collapse in terms of both percent cover and abundance until at least 2030. Outplanting, however, is a costly endeavor that many Caribbean nations may not be able to afford. If Acropora palmata nursery output and costs were to match those of $A$. cervicornis, planting 3000 $\mathrm{SC} 2$ colonies per year for $5 \mathrm{yr}$ would result in roughly $30 \%$ cover and would cost approximately US\$3M (T. Moore pers. comm.). Due to its cost, outplanting should be considered as part of a shortterm solution in a limited geographical region, rather than a comprehensive solution for this basinwide problem.

Why does an influx of small individuals only slightly improve population projections? The first explanation is that the smaller size classes do not have a significant influence over population growth as demonstrated by elasticity analyses. The relatively slow growth and high mortality of the individuals limit their demographic potential for the population. But the more relevant question is, why, even if we eliminate the possibility of a 'bad year' $(h=\infty)$, does this population seem incapable of recovering? Quite simply, the probability of shrinking, across all size classes and years (mean $\pm \mathrm{SE}, 0.089 \pm 0.014$ ), is roughly equivalent but slightly greater, than that of growing $(0.082 \pm 0.019)$. This implies that stressors causing the loss of tissue (e.g. disease, predation) are keeping pace with the ability of Acropora palmata to thrive even in the absence of hurricanes. More importantly, it implies that present vital rates during non-hurricane years are fundamentally different from those of the past, as recovery, even in the impossible case of no future disturbance, appears extremely unlikely to occur.

Our findings are somewhat in contrast to Lirman's (2003) stage-based population model of Acropora palmata in the northern Florida Keys, and the differences could highlight an important aspect of this organism's population dynamics and potential for recovery. Lirman parameterized his model from 1993 to 1997 on Elkhorn Reef, which at the time had a higher density of colonies than the sites described in the present study (D. Lirman pers. comm.). In Lirman's projections, storms recurring every $5 \mathrm{yr}$ resulted in a 4 -fold increase, from 10 to 50 colonies, after 50 yr. In contrast, in our study, parameterized a decade later with storms occurring every $6 \mathrm{yr}$, abundance decreased by $80 \%$, from 270 to 45 colonies $(95 \% \mathrm{CI}=3$ to 186 colonies), after $50 \mathrm{yr}$. The effects of the storms and/or the parameterization of storm effects could account for this difference; however, relative changes in transition matrix elements, especially in the influential rate of stasis for the largest colonies, between 
background and storm matrices, were comparable in the 2 studies. Alternatively, A. palmata could exhibit positive density dependence, as some observations suggest (Baums et al. 2003, Williams et al. 2008), wherein denser stands retain fragments and recover more quickly from storms than less dense stands. This hypothesis could be explored in a theoretical modeling exercise, for example, or using a model parameterized in an experimental outplanting design, with various densities of outplants in replicate plots. Further research in this area is critical, as a densitydependent model may demonstrate that percent cover could increase more quickly than our projections suggest.

\section{CONCLUSIONS}

Despite being protected under the US Endangered Species Act and being contained within notake marine reserves, our results show that without intervention, Acropora palmata in the Florida Keys will likely become functionally extinct in the near future. With intervention, population projections are highly variable, but active management offers the only positive prospect in the short term. Removing snails would likely have a net positive effect on population trajectories, although this process is resource intensive. Outplanting is projected to bolster demographics in the short term, but should be employed only in concert with the hard work of improving environmental conditions over the medium term (e.g. removing excess nutrients from sea water, restoring herbivorous fishes and invertebrates that remove macroalgae) and long term (e.g. reducing sea surface temperature and ocean acidification to pre-industrial age levels). Preserving and restoring the A. palmata population of northern Florida will undoubtedly be challenging, but will ensure the livelihood of untold numbers of shallow reef fish and invertebrates that depend on the complex habitat it provides. Sixty-six coral species are currently proposed for inclusion on the US Endangered Species List, none of which has demographic data comparable to that of the $A$. palmata population studied herein. As coral reefs face significant global threats, the much studied and cared for reefs of Florida will make an excellent example of how to bring a clonal, sessile, endangered organism back from the brink of extirpation. We hope that the model presented here will provide context in the potential listing and recovery planning of those candidate species as well.
Acknowledgements. The authors thank Margaret Miller, Brice Semmens, Nancy Knowlton, Jeremy Jackson, George Sugihara, and Sach Sokol for helpful guidance and critical thinking; and Jennifer Moore and NOAA's Coral Reef Conservation Program for generous funding.

\section{LITERATURE CITED}

Acevedo R, Morelock J, Olivieri RA (1989) Modification of coral reef zonation by terrigenous sediment stress. Palaios 4:92-100

Acropora Biological Review Team (2005) Atlantic Acropora status review. Report to National Marine Fisheries Service, Southeast Regional Office, St Petersburg, FL

> Adey W, Adey P, Burke R, Kaufman L (1977) The Hologene reef systems of eastern Martinique, French West Indies. Atoll Res Bull 218:1-40

$>$ Bak R, Engel M (1979) Distribution, abundance and survival of juvenile hermatypic corals (Scleractinia) and the importance of life history strategies in the parent coral community. Mar Biol 54:341-352

Baums IB, Miller MW, Szmant AM (2003) Ecology of a corallivorous gastropod, Coralliophila abbreviata, on two scleractinian hosts. I: Population structure of snails and corals. Mar Biol 150:1215-1225

Bruckner A, Hourigan T (2000) Proactive management for conservation of Acropora cervicornis and Acropora palmata: application of the U.S. Endangered Species Act. Proc 9th Int Coral Reef Symp 2:661-666

Carpenter KE, Abrar M, Aeby G, Aronson RB and others (2008) One-third of reef-building corals face elevated extinction risk from climate change and local impacts. Science 321:560-563

Caswell H (2001) Matrix population models: construction, analysis, and interpretation. Sinauer Associates, Sunderland, MA

del Mónaco C, Noriega N, Narciso S (2011) Note on density and predation rate of Coralliophila abbreviata and Coralliophila caribaea on juvenile colonies of Acropora palmata in a deteriorated coral reef of Cayo Sombrero, Morrocoy National Park, Venezuela. Lat Am J Aquat Resour 39:161-166

> Doak D, Morris W (1999) Detecting population-level consequences of ongoing environmental change without longterm monitoring. Ecology 80:1537-1551

> Edmunds PJ (2010) Population biology of Porites astreoides and Diploria strigosa on a shallow Caribbean reef. Mar Ecol Prog Ser 418:87-104

> Edmunds PJ, Carpenter R (2001) Recovery of Diadema antillarum reduces macroalgal cover and increases abundance of juvenile corals on a Caribbean reef. Proc Natl Acad Sci USA 98:5067-5071

Fong P, Glynn PW (1998) A dynamic size-structured population model: Does disturbance control size structure of a population of the massive coral Gardineroseris planulata in the Eastern Pacific? Mar Biol 130:663-674

Gardner TA, Coté IM, Gill JA, Grant A, Watkinson AR (2005) Hurricanes and Caribbean coral reefs: impacts, recovery, patterns, and role in long-term decline. Ecology 86:174-184

Geister J (1977) The influence of wave exposure on the ecological zonation of Caribbean coral reefs. Proc 3rd Int Coral Reef Symp, p 23-29 
Goreau T (1959) The ecology of Jamaican coral reefs I. Species composition and zonation. Ecology 40:67-90

Harvell CD, Kim K, Burkholder JM, Colwell RR and others (1999) Emerging marine diseases - climate links and anthropogenic factors. Science 285:1505-1510

Harvell CD, Jordán-Dahlgren E, Merkel S, Rosenberg E and others (2007) Coral disease, environmental drivers, and the balance between coral and microbial associates. Oceanography 20:172-195

> Highsmith RC (1982) Reproduction by fragmentation in corals. Mar Ecol Prog Ser 7:207-226

Highsmith R, Riggs A, D'Antonio CM (1980) Survival of hurricane-generated coral fragments and a disturbance model of reef calcification/growth rates. Oecologia 46: 322-329

Holmes G, Johnstone RW (2010) Modelling coral reef ecosystems with limited observational data. Ecol Model 221: 1173-1183

Hubbard D, Zankl H, Van Heerden I, Gill I (2005) Holocene reef development along the northeastern St. Croix Shelf, Buck Island, US Virgin Islands. J Sediment Res 75: 97-113

Hubbard D, Burke R, Gill I, Ramirez W, Sherman C (2008) Coral-reef geology: Puerto Rico and the US Virgin Islands. In: Riegl B, Dodge R (eds) Coral reefs of the USA. Springer, Dania Beach, FL, p 263-302

> Hughes T (1984) Population dynamics based on individual size rather than age: a general model with a reef coral example. Am Nat 123:778-795

Hughes TP, Connell JH (1987) Population dynamics based on size or age? A reef-coral analysis. Am Nat 129: 818-829

Hughes TP, Tanner JE (2000) Recruitment failure, life histories, and long-term decline of Caribbean corals. Ecology 81:2250-2263

IUCN (International Union for Conservation of Nature) (2011) The IUCN Red List of Threatened Species. Version 2011.1. Available at www.iucnredlist.org (accessed 2 August 2011)

Jackson JBC (1992) Pleistocene perspectives on coral-reef community structure. Am Zool 32:719-731

- Jackson JBC, Kirby MX, Berger WH, Bjorndal KA and others (2001) Historical overfishing and the recent collapse of coastal ecosystems. Science 293:629-637

> Jones RJ, Bowyer J, Hoegh-Guldberg O, Blackall LL (2004) Dynamics of a temperature-related coral disease outbreak. Mar Ecol Prog Ser 281:63-77

Kline DI, Kuntz NM, Breitbart M, Knowlton N, Rohwer F (2006) Role of elevated organic carbon levels and microbial activity in coral mortality. Mar Ecol Prog Ser 314: 119-125

Knowlton N, Lang JC, Keller BD (1990) Case study of natural population collapse: post-hurricane predation on Jamaican staghorn corals. Smithson Contrib Mar Sci 31: $1-26$

Editorial responsibility: David Hodgson, University of Exeter, Cornwall Campus, UK
Lang JC (ed) (2003) Status of coral reefs in the western Atlantic: results of initial surveys, Atlantic and Gulf Rapid Reef Assessment (AGRRA) program. Atoll Res Bull 496:1-635

> Lirman D (2000) Fragmentation in the branching coral Acropora palmata (Lamarck): growth, survivorship, and reproduction of colonies and fragments. J Exp Mar Biol Ecol 251:41-57

- Lirman D (2003) A simulation model of the population dynamics of the branching coral Acropora palmata - effects of storm intensity and frequency. Ecol Model 161:169-182

Lirman D, Fong P (1997) Patterns of damage to the branching coral Acropora palmata following Hurricane Andrew: damage and survivorship of hurricane-generated asexual recruits. J Coast Res 13:67-72

Miller M (2001) Corallivorous snail removal: evaluation of impact on Acropora palmata. Coral Reefs 19:293-295

Miller MW, Baums IB, Williams DE (2007) Visual discernment of sexual recruits is not feasible for Acropora palmata. Mar Ecol Prog Ser 335:227-231

NOAA (National Oceanic and Atmospheric Administration) (2011) Historical hurricane tracks. Available at www.csc. noaa.gov/hurricanes/\# (accessed 29 March 2011)

NMFS (National Marine Fisheries Service (2010) Endangered and threatened wildlife; notice of 90-day finding on a petition to list 83 species of corals as Threatened or Endangered under the Endangered Species Act (ESA). Fed Regist 75:6616-6621

R Development Core Team (2011) R: a language and environment for statistical computing. R Foundation for Statistical Computing, Vienna

> Rogers C (1983) Sublethal and lethal effects of sediments applied to common Caribbean reef corals in the field. Mar Pollut Bull 14:378-382

> Soong K, Lang JC (1992) Reproductive integration in reef corals. Biol Bull (Woods Hole) 183:418-431

Stubben C, Milligan B (2007) Estimating and analyzing demographic models using the popbio package in $\mathrm{R}$. J Stat Softw 22:1-23

Tuljapurkar S, Horvitz CC, Pascarella JB (2003) The many growth rates and elasticities of populations in random environments. Am Nat 162:489-502

Williams DE, Miller MW (2012) Attributing mortality among drivers of population decline in Acropora palmata in the Florida Keys (USA). Coral Reefs 31:369-382

Williams DE, Miller MW, Kramer KL (2006) Demographic monitoring protocols for threatened Caribbean Acropora spp. corals. Tech Memo NMFS-SEFSC-543. NOAA, Miami, FL

> Williams DE, Miller MW, Kramer KL (2008) Recruitment failure in Florida Keys Acropora palmata, a threatened Caribbean coral. Coral Reefs 27:697-705

Woodley JD, Chornesky EA, Clifford PA, Jackson JBC and others (1981) Hurricane Allen's impact on Jamaican coral reefs. Science 214:749-755

Submitted: November 23, 2011; Accepted: November 2, 2012 Proofs received from author(s): December 12, 2012 